\title{
Impact of Video Describing Cataract Surgical Simulator Training on Patients' Perceptions of Resident Involvement in Cataract Surgery
}

\author{
Zachary C. Landis, $\mathrm{MD}^{1,2}$ John B. Fileta, $\mathrm{MD}^{1,2}$ \\ Ingrid U. Scott, MD, MPH ${ }^{1,3}$ \\ ${ }^{1}$ Department of Ophthalmology, Penn State College of Medicine, \\ Hershey, Pennsylvania \\ 2 Eye Associates of Lancaster, Lancaster, Pennsylvania \\ ${ }^{3}$ Department of Public Health Sciences, Penn State College of \\ Medicine, Hershey, Pennsylvania
}

\author{
Allen R. Kunselman, $\mathrm{MA}^{3}$ Joseph Sassani, $\mathrm{MD}^{1}$
}

J Acad Ophthalmol 2021;13:e96-e101.

\begin{abstract}
Address for correspondence Ingrid U. Scott, MD, MPH, Departments of Ophthalmology and Public Health Sciences, Penn State College of Medicine, 500 University Dr, HU19, Hershey, PA 17033-0850 (e-mail: iscott@pennstatehealth.psu.edu).
\end{abstract}

\begin{abstract}
Keywords

- cataract surgical simulator

- cataract surgery simulator

- virtual reality

- cataract surgery training

- ophthalmology resident training
\end{abstract}

Purpose The aim of this article is to investigate the impact of a 1-minute video describing resident training with a cataract surgical simulator on patients' perceptions regarding resident involvement in cataract surgery and to identify factors associated with patient willingness to have cataract surgery performed by a resident.

Design Cross-sectional survey.

Methods An anonymous Likert-style survey was conducted among 430 consecutive adult patients who presented for eye examination at the Penn State Health Eye Center. The survey included questions regarding demographics, understanding of the medical training hierarchy, and patient willingness to have a resident perform their cataract surgery. There were six questions regarding patient willingness to have residents perform their cataract surgery and the second question in this set informs the patient that residents are supervised by an experienced cataract surgeon. Patients were randomly assigned to one of two groups: patients in Group 1 completed the survey only, while patients in Group 2 watched a 1-minute video describing resident training with a cataract surgical simulator prior to completing the survey.

Results Four hundred fourteen of the 430 patients (96.3\%) completed the survey. Overall, $24.7 \%(n=102)$ of respondents expressed willingness to allow an ophthalmology resident to perform their cataract surgery, and that proportion increased to $54.0 \%$ $(n=223)$ if the patient was informed that the resident would be supervised by an experienced cataract surgeon. Patients in Group 2 were twice as likely compared with patients in Group 1 to express willingness to allow an ophthalmology resident to perform their cataract surgery (odds ratio 1.92 [1.18-3.11], $p=0.009$ ).

Conclusions A thorough informed consent process including information regarding attending supervision and a brief video detailing resident training with a cataract surgery simulator may increase patient willingness to allow resident participation in cataract surgery. received

October 26, 2020 accepted after revision February 2, 2021
DOI https://doi.org/ 10.1055/s-0041-1728659. ISSN 2475-4757.

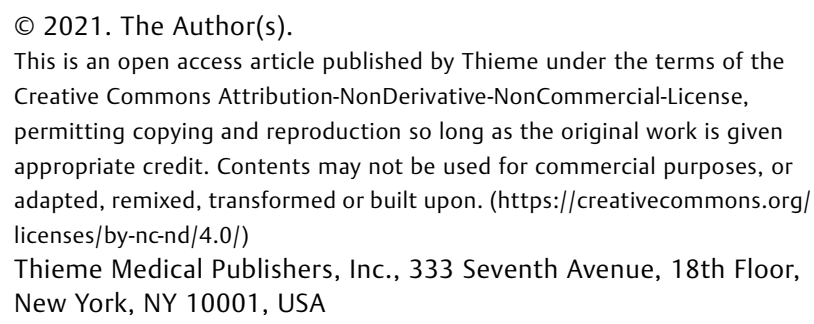


Cataract remains a leading cause of vision loss in the United States and worldwide, and cataract surgery rates continue to rise in developed countries. ${ }^{1}$ As the demand for cataract surgery continues to increase, high-quality cataract surgical training during ophthalmology residency is essential. The Accreditation Council for Graduate Medical Education (ACGME) requires that residents perform a minimum of 86 cataract surgeries as primary surgeon prior to graduation; the majority of ophthalmology residents perform over twice this number. 2,3

Cataract surgery presents a steep learning curve for the novice resident surgeon. Resources such as wet laboratories and surgical simulators can help residents learn the microsurgical techniques of intraocular surgery before performing surgery on a patient. In fact, the ACGME now requires that ophthalmology residency programs have a resource available to residents for surgical skills development, either in the form of a wet laboratory or a surgical simulator. ${ }^{4}$

Surgical simulators have garnered considerable attention as a useful stepping stone to performing cataract surgery on patients, offering residents the opportunity to hone fine motor skills required to perform microsurgery in a controlled setting without risk of harm. Various eye surgery simulators are currently available, including EYESi (VRMagic), PhacoVision (Melerit Medical), and MicrovisTouch (ImmersiveTouch). Several studies have demonstrated that surgical simulators are equally effective to traditional wet laboratories with respect to improving resident performance in various steps of cataract surgery. ${ }^{5-8}$ Surgical simulators may be most beneficial to less surgically adept residents and may identify residents who require additional training in cataract surgery. ${ }^{9,10}$

Even in the most experienced hands, complications can occur during cataract surgery. A central tenet of medical ethics and the Hippocratic oath is primum non nocere, or do no harm. The risk of harm in the operating room may be minimized by residents training on surgical simulators and in wet laboratories prior to operating on patients. Another essential principle in medical ethics is patient autonomy. As cataract surgery is almost always an elective procedure, patients have significant autonomy regarding who performs their surgery. An honest discussion between surgeon and patient about resident involvement with cataract surgery is essential to the patient's ability to give informed consent.

Previous studies have reported variable results regarding patients' willingness to have residents perform their cataract surgery, ranging from very low (16\%) to very high (95\%). ${ }^{11-14}$ One study reported a range of 21 to $86 \%$ even among patients living in the same geographic location. ${ }^{13}$ Another study reported that although most patients are willing to have residents assist with their cataract surgery if patients are fully informed and asked in advance, one-quarter of these patients reported they would be likely or very likely to seek treatment elsewhere if residents were the primary surgeon of their cataract surgery. ${ }^{14}$
To our knowledge, and based on a search of the PubMed literature database, there is no published information on the potential impact of resident training with a cataract surgical simulator on patients' willingness to have residents perform their cataract surgery. The purpose of the current study is to investigate the impact of a 1-minute Video describing resident training with a cataract surgical simulator on patients' perceptions regarding resident involvement in cataract surgery and to identify factors associated with patient willingness to have cataract surgery performed by a resident.

\section{Methods}

The study protocol was approved by the Institutional Review Board of the Penn State College of Medicine. An anonymous Likert-style survey was provided to 430 consecutive adult patients who presented for eye examination at the Penn State Health Eye Center. Study participants included patients presenting for cataract evaluation, patients with a history of cataract surgery, and patients presenting for numerous other reasons, including routine eye examinations and appointments within subspecialty clinics including cornea, glaucoma, retina, oculoplastics, and neuro-ophthalmology. Surveys were distributed by office staff who checked the patients into the eye clinic and were self-administered or administered with the assistance of a person accompanying the patient to the appointment.

The survey included questions regarding demographics and understanding of the medical training hierarchy, and Likert-style statements to assess patient willingness to have a resident perform their cataract surgery (-Supplemental Material S1 [online only]). Demographic information collected included age, gender, ethnicity and level of education.

Patients were randomly assigned to one of two groups: patients in Group 1 were asked to complete the survey, while patients in Group 2 watched a 1-minute video (on a tablet) describing resident training with a cataract surgical simulator (EyeSi, VR Magic, Mannheim, Germany) prior to filling out the survey. The video was created by the authors and highlighted features of the simulator, including the components of the simulator and their relation to real surgical instruments and the training regimen for residents using the simulator at our institution ( - Video 1 [online only]).

\section{Video 1}

Online content including video sequences viewable at: https://www.thieme-connect.com/products/ ejournals/html/10.1055/s-0041-1728659.

Demographic and survey response data were compared between groups using two-sample t-tests for continuous variables and chi-square tests for categorical variables. Logistic regression was then used to control for age, gender, ethnicity, education, and prior cataract surgery. 


\section{Results}

Four hundred fourteen of the 430 patients (96.3\%) completed the survey, including 207 in Group 1 and 207 in Group 2. The average age of patients in Group 1 was younger than patients in Group 2 ( $57.8 \pm 16.6$ vs. $64.6 \pm 16.1$ years, $p<0.001)$; there were no other significant differences in demographics between the two groups ( - Table 1 ). There were significantly more patients in Group $2(n=79$ [38.2\%]) than in Group 1 $(n=58[28.0 \%])$ who had previously undergone cataract surgery $(p=0.0288)$. There were no other differences between the two groups with regard to proportion of patients who had previously undergone any type of eye surgery (Group $1 n=89$ [43.0\%] vs. Group $2 n=84$ [40.6\%], $p=0.61840$ ) or proportion scheduled for cataract surgery to be performed in the next 60 days (Group $1 n=8$ [3.9\%] vs. Group $2 n=7$ [3.4\%], $p=0.8705$ ). There was also no significant difference between the groups in patients' understanding of the levels of training in medicine (-Table 2 ).

Overall, $24.7 \%(n=102)$ of respondents expressed willingness (a response of agree or strongly agree) to allow an ophthalmology resident to perform their cataract surgery, and that proportion increased to $54.0 \%(n=223)$ if the resident was supervised by an experienced cataract surgeon. Significantly more patients in Group 2 reported they would feel comfortable having an eye surgeon in training perform their cataract surgery if the trainee had already successfully performed cataract surgery on a surgical simulator (Group 1 $n=7034.1$ vs. Group $2 n=101$ [48.8\%], $p=0.002$ ). After controlling for age, gender, ethnicity, education, and prior cataract surgery, patients in Group $2(31.1 \%, n=64)$ were significantly more likely than patients in Group $1(18.4 \%$, $n=38$ ) to express willingness to allow an ophthalmology resident to perform their cataract surgery (odds ratio [OR]: 1.92 [1.18-3.11], $p=0.009$ ). The difference between Group 1 $(48.3 \%, n=100)$ and Group $2(59.7 \%, n=123)$ was borderline statistically significant if the resident was supervised by an experienced cataract surgeon (OR: 1.50 [1.00-2.27], $p=0.051)$ (-Table 3).

Ninety-five percent $(n=392)$ of all patients agreed or strongly agreed that they should be informed if their cataract surgery is to be performed by a resident ( - Table 3 ). Controlling for age, gender, ethnicity, education, and prior cataract surgery, the proportion of patients who agreed or strongly agreed that they would be less likely to have cataract surgery performed at a hospital where a resident performs their cataract surgery was not significantly different between Groups 1 and 2 ( 32.5 vs. $30.4 \%$, respectively; $p=0.521$ ). Similarly, there was no significant difference between Groups 1 and 2 in the proportion of respondents who agreed or strongly agreed that they would not have cataract surgery performed at a hospital where a resident performs their cataract surgery supervised by an experienced cataract surgeon ( 26.2 vs. $23.7 \%$, respectively; $p=0.498$ ).

\section{Discussion}

To our knowledge, and based on a computerized search of the PubMed literature, the current study represents the first investigation of the impact of a video describing resident training with a cataract surgical simulator on patients' perceptions regarding resident involvement in cataract

Table 1 Baseline demographics

\begin{tabular}{|c|c|c|c|c|}
\hline & Cumulative data & Group 1 & Group 2 & $p$-Value \\
\hline Age $(y)$ & $61.2 \pm 16.4$ & $57.8 \pm 16.6$ & $64.6 \pm 16.1$ & $<0.001$ \\
\hline \multicolumn{4}{|l|}{ Gender } & \multirow[t]{3}{*}{0.059} \\
\hline Female & $235(56.8 \%)$ & $127(61.4 \%)$ & $108(52.2 \%)$ & \\
\hline Male & $179(43.2 \%)$ & $80(38.6 \%)$ & $99(47.8 \%)$ & \\
\hline \multicolumn{4}{|l|}{ Ethnicity } & \multirow[t]{5}{*}{0.817} \\
\hline White & $363(88.5 \%)$ & $181(87.9 \%)$ & $182(89.2 \%)$ & \\
\hline African American & $23(5.6 \%)$ & $11(5.3 \%)$ & $12(5.9 \%)$ & \\
\hline Hispanic & $11(2.7 \%)$ & $7(3.4 \%)$ & $4(2.0 \%)$ & \\
\hline Other & $13(3.2 \%)$ & $7(3.4 \%)$ & $6(2.9 \%)$ & \\
\hline \multicolumn{4}{|l|}{ Education } & \multirow[t]{5}{*}{0.170} \\
\hline$<$ High school & $28(6.8 \%)$ & $14(6.8 \%)$ & $14(6.8 \%)$ & \\
\hline High school/GED & $173(42.2 \%)$ & $76(37.1 \%)$ & $97(47.3 \%)$ & \\
\hline College & $132(32.2 \%)$ & 75 (36.6\%) & $57(27.8 \%)$ & \\
\hline Graduate school & 77 (18.8\%) & 40 (19.5\%) & 37 (18.0\%) & \\
\hline
\end{tabular}

Group 1 = subjects who did not watch the video prior to survey completion. Group 2 =subjects who watched a short video explaining the role of surgical simulators in resident training prior to survey completion. Total $n=414$; however, not all patients completed all demographic information (4 patients in Group 2 did not report age, 1 patient in Group 1 and 3 patients in Group 2 did not report ethnicity, 2 patients in Group 1 and 2 patients in Group 2 did not report education). 
Table 2 Patients' correct responses to questions assessing understanding of medical training hierarchy

\begin{tabular}{|c|c|c|c|c|c|}
\hline Statement & Cumulative data & Group 1 & Group 2 & Odds ratio $(95 \% \mathrm{Cl})$ & p-Value \\
\hline $\begin{array}{l}\text { A medical student } \\
\text { is a medical doctor } \\
\text { (false) }\end{array}$ & 374 (91\%) & $189(92.2 \%)$ & $185(90.7 \%)$ & $1.40(0.66-2.99)$ & 0.379 \\
\hline $\begin{array}{l}\text { A resident has } \\
\text { completed medical } \\
\text { school (true) }\end{array}$ & 334 (81.9\%) & $161(79.3 \%)$ & $173(84.4 \%)$ & $1.43(0.81-2.53)$ & 0.218 \\
\hline $\begin{array}{l}\text { An attending } \\
\text { requires supervi- } \\
\text { sion by a resident } \\
\text { (false) }\end{array}$ & $197(50.3 \%)$ & $105(55.3 \%)$ & 92 (45.5\%) & $1.22(0.80-1.88)$ & 0.358 \\
\hline $\begin{array}{l}\text { A resident requires } \\
\text { no supervision to } \\
\text { perform surgery } \\
\text { (false) }\end{array}$ & $332(82.2 \%)$ & $162(81.4 \%)$ & $170(82.9 \%)$ & $0.77(0.45-1.33)$ & 0.356 \\
\hline $\begin{array}{l}\text { Medical students } \\
\text { and residents are at } \\
\text { different levels of } \\
\text { training (true) }\end{array}$ & $392(96.6 \%)$ & $192(95.5 \%)$ & $200(97.6 \%)$ & $1.54(0.47-5.09)$ & 0.480 \\
\hline
\end{tabular}

Abbreviation: $\mathrm{Cl}$, confidence interval.

Group 1 = subjects who did not watch the video prior to survey completion. Group 2 =subjects who watched a short video explaining the role of surgical simulators in resident training prior to survey completion.

Table 3 Rates of agreement with survey statements

\begin{tabular}{|c|c|c|c|c|}
\hline Statement & Group & $\begin{array}{l}\text { Agree or strongly } \\
\text { agree }\end{array}$ & Odds ratio $(95 \% \mathrm{Cl})$ & $p$-Value \\
\hline $\begin{array}{l}\text { I would feel comfortable having an eye } \\
\text { surgeon in training perform my cataract } \\
\text { surgery }\end{array}$ & $\begin{array}{l}1(n=207) \\
2(n=206)\end{array}$ & $\begin{array}{l}18.4 \%(n=38) \\
31.1 \%(n=64)\end{array}$ & $1.92(1.18-3.11)$ & 0.009 \\
\hline $\begin{array}{l}\text { I would feel comfortable having an eye } \\
\text { surgeon in training perform my cataract } \\
\text { surgery as long as the trainee is super- } \\
\text { vised by an experienced cataract surgeon }\end{array}$ & $\begin{array}{l}1(n=207) \\
2(n=206)\end{array}$ & $\begin{array}{l}48.3 \%(n=100) \\
59.7 \%(n=123)\end{array}$ & $1.50(1.00-2.27)$ & 0.051 \\
\hline $\begin{array}{l}\text { I would feel comfortable having an eye } \\
\text { surgeon in training perform my cataract } \\
\text { surgery if the trainee had already suc- } \\
\text { cessfully performed cataract surgery on a } \\
\text { surgical simulator }\end{array}$ & $\begin{array}{l}1(n=205) \\
2(n=207)\end{array}$ & $\begin{array}{l}34.1 \%(n=70) \\
48.8 \%(n=101)\end{array}$ & $1.97(1.30-3.00)$ & 0.002 \\
\hline $\begin{array}{l}\text { If my cataract surgery would be per- } \\
\text { formed by an eye surgeon in training who } \\
\text { would be supervised by an experienced } \\
\text { cataract surgeon, I would be less likely to } \\
\text { have my cataract surgery at this hospital }\end{array}$ & $\begin{array}{l}1(n=207) \\
2(n=206)\end{array}$ & $\begin{array}{l}32.4 \%(n=67) \\
30.6 \%(n=63)\end{array}$ & $0.87(0.56-1.35)$ & 0.521 \\
\hline $\begin{array}{l}\text { If my cataract surgery would be per- } \\
\text { formed by an eye surgeon in training who } \\
\text { would be supervised by an experienced } \\
\text { cataract surgeon, I would NOT have my } \\
\text { cataract surgery at this hospital }\end{array}$ & $\begin{array}{l}1(n=205) \\
2(n=206)\end{array}$ & $\begin{array}{l}26.3 \%(n=54) \\
23.8 \%(n=49)\end{array}$ & $0.85(0.52-1.37)$ & 0.498 \\
\hline $\begin{array}{l}\text { I should be informed if my cataract sur- } \\
\text { gery is to be performed by an eye surgeon } \\
\text { in training }\end{array}$ & $\begin{array}{l}1(n=206) \\
2(n=207)\end{array}$ & $\begin{array}{l}94.2 \%(n=194) \\
95.7 \%(n=198)\end{array}$ & $2.03(0.75-5.50)$ & 0.162 \\
\hline
\end{tabular}

Abbreviation: $\mathrm{Cl}$, confidence interval.

Group 1 = subjects who did not watch the video prior to survey completion. Group 2 =subjects who watched a short video explaining the role of surgical simulators in resident training prior to survey completion. The differing $n$ values represent a patient not selecting an answer for that particular statement. 
surgery. Patients responding to the survey were more likely to express willingness to allow a resident to perform their cataract surgery if they first watched a 1-minute video demonstrating an ophthalmology resident training on a cataract surgical simulator and explaining that the resident must complete the surgical simulator training prior to performing cataract surgery on humans. However, when patients were informed the resident would be supervised by an experienced cataract surgeon, the impact of watching the video on patient willingness to have their cataract surgery performed by a resident was only borderline significant; of note, a larger sample size may have yielded a statistically significant result. Thus, both informing the patient that the resident would be supervised by an experienced cataract surgeon and showing the patient a video describing resident training with a cataract surgical simulator increases a patient's comfort level with having a resident perform the cataract surgery. About one-quarter of patients expressed that they would not have cataract surgery at a hospital where a resident performed their cataract surgery even if the residents were supervised by an experienced cataract surgeon; having patients watch the video describing resident training on a cataract surgical simulator did not have a significant impact on this proportion.

Previous studies have reported a wide range of results regarding patients' willingness to have residents perform their cataract surgery, ranging from 16 to $95 \% .^{11-14}$ The current study found that $24.6 \%$ of patients expressed willingness to have a resident perform their cataract surgery and this number increased to $53.9 \%$ if they were informed the resident would be supervised by an experienced cataract surgeon. Reasons patients may be unwilling to have a resident perform their surgery may be previous unfavorable experience with a resident, lack of prior experience with a resident, and poor understanding of the role and level of experience of a resident. In contrast, patients may be more willing to have a resident perform their care if they have had previous favorable interactions with residents, and if they understand the role and level of training of residents.

The current study found that patients who watched a 1minute video explaining the training that residents undergo before performing cataract surgery in a patient are more likely to express a willingness to allow an ophthalmology resident to perform their cataract surgery (30.9 vs. $18.4 \%$ ), and this difference remained significant even after controlling for age, gender, ethnicity, education, and prior cataract surgery. However, the percentage of patients that reported they would be comfortable with resident-performed cataract surgery increased even more with the knowledge that they would be supervised by an experienced surgeon rather (54.0 vs. 30.9\%). The level of resident supervision during cataract surgery is vital to discuss during the consent process. This ensures that patients are well educated regarding their care team.

There are limitations of this study. The survey was completed by patients while waiting for an eye examination at an academic teaching hospital; it is possible that the subjects' responses may be biased either positively or negatively by seeking care in this setting. Additionally, the wording and ordering of questions can leave some areas for interpretation by the subject. For example, statement 3 ( - Table 3 ) leaves the aspect of attending supervision to interpretation; the subjects may have interpreted this statement as being with or without attending supervision in the setting of surgical simulator training. Likewise, statement 1 (-Table 3 ) also leaves the role of attending supervision up to interpretation. If the patient was informed that all resident cataract surgeries are supervised by an attending physician, this number would likely be higher (as is reflected in statement 2).

Another limitation of this survey is the relatively homogenous patient population. The patients included in this study were $88.5 \%$ Caucasian, which is not representative of the United States population as a whole. Additionally, the majority (51.0\%) of patients reported having a college education or greater. While these variables were controlled for in the analysis, this may limit the external validity of these results for patients in other practice settings.

A recent study identified trust in the attending surgeon, assurance of resident supervision, and belief in contributing to future physician education as factors that contributed to patient consent to resident involvement in surgery, while fear and trust only in the attending surgeon were factors that contributed to patients not consenting to resident involvement in surgery. ${ }^{15}$ We believe that being transparent about the resident surgical training process and their roles in surgery is essential to optimizing the patient-physician relationship. Limited time can be a barrier in health care, but the use of a video or even a small brochure demonstrating the preparation a resident physician undergoes prior to performing surgery on patients can help make patients more aware of the medical hierarchy, the skills, and knowledge that residents acquire through successive years of training, and the level of supervision that takes place in an operating room setting.

The data presented in this study and previous studies support that patients are more willing to have residents perform their cataract surgery if they are informed that the resident is supervised by an experienced cataract surgeon. This study also demonstrates that a brief video detailing resident training with a cataract surgery simulator is associated with increased patient willingness to allow a resident to perform cataract surgery.

\section{Disclosure}

Presented in part at the Association for Research in Vision and Ophthalmology annual meeting, May 3-7, 2015, Denver, Colorado.

None of the authors reports any financial or proprietary interest in the information presented.

\section{Conflict of Interest}

None.

\section{References}

1 Klein BEK, Howard KP, Lee KE, Klein R. Changing incidence of lens extraction over 20 years: the Beaver Dam eye study. Ophthalmology 2014;121(01):5-9 
2 Accreditation Council for Graduate Medical Education. Required minimum number of procedures for graduating residents in ophthalmology: review committee for ophthalmology, 2013. Accessed March 8, 2021 at: https://www.acgme.org/Portals/0/PFAssets/ProgramResources/240_Oph_Minimum_Numbers.pdf

3 Lotfipour M, Rolius R, Lehman EB, Pantanelli SM, Scott IU. Trends in cataract surgery training curricula. J Cataract Refract Surg 2017;43(01):49-53

4 Accreditation Council for Graduate Medical Education. Required minimum number of procedures for graduating residents in ophthalmology, 2014. Accessed March 8, 2021 at: https:// www.acgme.org/Portals/0/PFAssets/ProgramResources/ 240_Oph_Minimum_Numbers.pdf?ver=2015-11-06-120652043

5 Daly MK, Gonzalez E, Siracuse-Lee D, Legutko PA. Efficacy of surgical simulator training versus traditional wet-lab training on operating room performance of ophthalmology residents during the capsulorhexis in cataract surgery. J Cataract Refract Surg 2013;39(11):1734-1741

6 Belyea DA, Brown SE, Rajjoub LZ. Influence of surgery simulator training on ophthalmology resident phacoemulsification performance. J Cataract Refract Surg 2011;37(10):1756-1761

7 Bergqvist J, Person A, Vestergaard A, Grauslund J. Establishment of a validated training programme on the Eyesi cataract simulator. A prospective randomized study. Acta Ophthalmol 2014;92(07): 629-634
8 McCannel CA, Reed DC, Goldman DR. Ophthalmic surgery simulator training improves resident performance of capsulorhexis in the operating room. Ophthalmology 2013;120(12):2456-2461

9 Pokroy R, Du E, Alzaga A, et al. Impact of simulator training on resident cataract surgery. Graefes Arch Clin Exp Ophthalmol 2013;251(03):777-781

10 Roohipoor R, Yaseri M, Teymourpour A, Kloek C, Miller JB, Loewenstein JI. Early performance on eye surgery simulator predicts subsequent resident surgical performance. J Surg Educ 2017;74(06):1105-1115

11 Nguyen TN, Silver D, Arthurs B. Consent to cataract surgery performed by residents. Can J Ophthalmol 2005;40 (01):34-37

12 Gan KD, Rudnisky CJ, Weis E. Discussing resident participation in cataract surgery. Can J Ophthalmol 2009;44(06):651-654

13 Sharda RK, Sher JH, Chan BJ, Kobetz LE, Mann KD. A comparison of techniques: informed consent for resident involvement in cataract surgery. Can J Ophthalmol 2012;47(02):113-117

14 Wisner DM, Quillen DA, Benderson DM, Green MJ. Patient attitudes toward resident involvement in cataract surgery. Arch Ophthalmol 2008;126(09):1235-1239

15 Corwin AM, Rajkumar JN, Markovitz BJ, et al. Association of preoperative disclosure of resident roles with informed consent for cataract surgery in a teaching program. JAMA Ophthalmol 2019;137(09):1045-1051 